Engineering History and Heritage Volume 168 Issue EH1

Climate threats to the earth-built heritage of Scotland

Parkin, Adderley, Kennedy et al.
Proceedings of the Institution of Civil Engineers Engineering History and Heritage 168 February 2015 Issue EH1 Pages 17-30 http://dx.doi.org/10.1680/ehah.14.00017 Paper 1400017

Received 13/08/2014_Accepted 30/10/2014 Published online 27/11/2014

Keywords: conservation/environment/weather

\title{
Climate threats to the earth-built heritage of Scotland
}

1 Simon J. Parkin MRes

Graduate Researcher, School of Natural Sciences, University of Stirling, Stirling, UK

2 W. Paul Adderley PhD

Director, Centre for Environmental History and Policy; Lecturer, School of Natural Sciences, University of Stirling, Stirling, UK

3 Craig J. Kennedy PhD

Senior Lecturer, School of the Built Environment, Heriot-Watt University, Edinburgh, UK
4 Yasemin Didem Aktas MSc, PhD

Research Associate, Epicentre Research Group, Civil, Environmental and Geomatic Engineering, University College London, London, UK

5 Dina D’Ayala Dr.Ing, Ing, PhD

Professor, Epicentre Research Group, Civil, Environmental and Geomatic Engineering, University College London, London, UK

6 Aykut Erkal MSc, PhD

Assistant Professor, Faculty of Engineering and Architecture, Civil Engineering Department, Istanbul Kemerburgaz University, Istanbul, Turkey
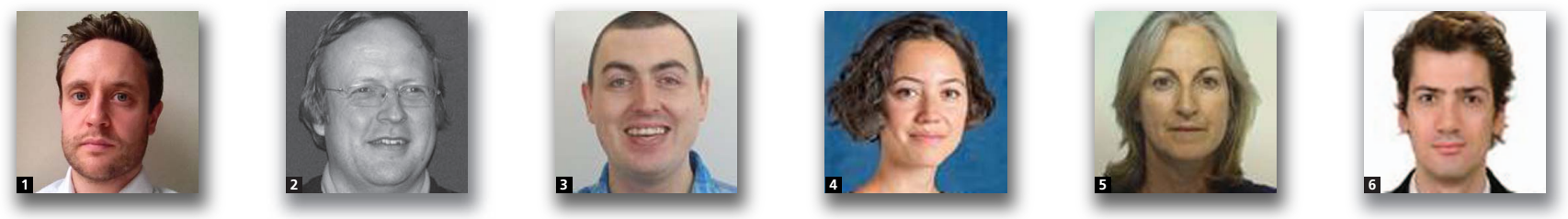

The most significant concentration of surviving vernacular mudwall structures in Scotland is found in and around the town of Errol in the Carse of Gowrie. Mudwall, or cob, is particularly susceptible to climate-related impacts such as water ingress and freeze-thaw cycles. A lack of recognition can exacerbate the effects of these factors significantly. Using two sites as representative case studies, this paper considers the issues typically encountered. The procedures used in monitoring the performance of each building within a regional climate context are outlined. Using climate models and current weather data, the local climatic context within which these structures exist is considered. Climate-related impacts can then be considered for future scenarios. Temperature and humidity data were collected concurrently from targeted areas within the walls of both structures for over a year from April 2012, a period that exhibited a range of extreme weather events in the Carse of Gowrie. The system of datalogging at each structure is discussed and results considered against external weather conditions using decomposed time series statistical analysis. Recommendations are offered considering how an integrated approach to the analysis of historic mudwall structures can be achieved.

\section{Introduction}

There are many potential future impacts of a changed climate on our built environment. These include direct and immediate impacts such as the effect of increased precipitation intensity and consequential flooding. Such catastrophic impacts are both newsworthy and readily comprehended by policy-makers and consequently receive a great deal of attention. Less direct impacts include changes to groundwater beneath buildings through increased precipitation and rising sea and river levels, as well as increased erosion of materials through the action of ice, wind and rain. While less catastrophic, such chronic impacts occur on an immense scale. Among the most sensitive structures within Britain's diverse collection of building styles and fabrics are those built from soil, or 'earth-built' structures. Vernacular earth-built structures were once a common dwelling type in many parts of Britain, spanning many locations and utilising a variety of vernacular materials including mass-earth (cob, mudwall, claywall), wattle and daub, and turf. Equally, a wide range of construction styles, including cruck-framing, were adopted across Great Britain in combination with earthen materials. With around 20000 examples, domestic cob buildings are still commonplace in the south-west of England (Keefe, 2005: p. 26) but, elsewhere, surviving historic earth buildings are rare and few contemporary equivalents are being constructed. Surviving buildings outside of the south-west of England therefore embody several tangible and intangible heritage elements: they represent an archive of lost craft practices and past construction styles and materials.

The earth buildings found in Scotland are among the most hidden of the built heritage in Great Britain, with few surviving examples. Some prominent buildings built of earth are known, 
Climate threats to the earth-

built heritage of Scotland

Parkin, Adderley, Kennedy et al. including Burns' Cottage at Alloway, although this example is better recognised for its past occupant than its construction. Errol, a small town that developed from the twelfth century through flax growing and processing, is sited on the estuarine clay of the Carse of Gowrie. This is an area of land finally drained in the eighteenth century and is located on the north bank of the River Tay. Errol and the Carse of Gowrie has the largest known concentration of earth-built structures in Scotland, with 40 surviving mudwall examples, five of which have some form of statutory protection. This represents a substantial percentage of the 105 earth-built buildings reported to have been constructed in this region between 1795 and 1903 (Morton and Winship, 2012).

The rarity of these buildings and the lack of a surviving craft tradition for their construction have led to issues regarding their conservation, notably the possibility of inappropriate repair and a lack of recognition of their place in the heritage landscape. The most major long-term threat is the impact of a changed climate. The study reported in this paper examined the reaction of the building materials to contemporary weather over one calendar year.

In this instance the present-day conditions found in Scotland may act as an actualistic model for future events (storms, temperature and precipitation extremes) elsewhere in Britain and northern Europe. The commonality in building style and materials between the mudwall constructions found at Errol and the Carse of Gowrie and cob buildings elsewhere emphasises the profound importance of this study.

\subsection{Projections of future climate in the Carse of Gowrie}

Acknowledging the implications of the series of Intergovernmental Panel on Climate Change (IPCC) reports produced since 1990, heritage custodians in Scotland have become increasingly aware of present and potential future climate-related impacts upon cultural heritage, with such concerns now being central to the remit of those who manage historic properties. As such, there is increased emphasis placed upon proactivity with regard to the conservation of cultural heritage, with recognition of the likelihood of new or altered damage functions related to continued climatic and environmental changes at the centennial scale (Historic Scotland, 2002, 2011, 2012). This reflects a wider awareness of the potential implications of climate change for the management of the built heritage across the UK and further afield, particularly since the turn of the millennium.

The UK climate projections (UKCP09) online data set provides national- and subnational-scale climate projections used to drive climate change mitigation policies in the UK, being funded by the UK government and devolved administrations (Met Office, 2014). The projected climate data provided by UKCP09 are the product of a number of climate models, including the Met Office Hadley Centre global climate model (HADCM3), which is used in its collaborative modelling activities. The UKCP09 data are given at a resolution of $25 \mathrm{~km}^{2}$ and are summarised graphically online for seven consecutive overlapping 30-year periods spanning 2010 to 2100 , in conjunction with modelled baseline data from which projections are derived. UKCP09 uses three of the Special Report on Emissions Scenarios (SRES) scenarios outlined by the IPCC alongside UK-focused climate science in order to project climatic changes resulting from high (SRES A1F1), medium (SRES A1B) and low (SRES B1) emissions scenarios over the course of the twenty-first century. Among the typical projections of UKCP09, within the context of variability across the regions, are increases to both daily minimum and daily maximum temperatures, limited change to annual mean precipitation but with increases to winter precipitation and decreases in summer precipitation and decreases in summer relative humidity (RH) (Jenkins et al., 2010).

UKCP09 also provides a 'weather generator' downscaling tool, allowing users to model the included variables at a more localised scale (Jones et al., 2009). This tool was used as a means of generating projected climate scenarios at a scale of $5 \mathrm{~km}^{2}$ centred on Errol. The UKCP09 weather generator uses precipitation sequences to generate four primary variables daily mean temperature, daily temperature range, vapour pressure and sunshine duration - which are then used to extrapolate the variables of daily minimum and maximum temperatures and $\mathrm{RH}$ that are of particular interest here. While the weather generator does not improve the reliability of projections, it does allow a valuable local data repository to be developed relevant to a specific area of interest and provides daily or hourly, rather than monthly or seasonal, temporal resolution. This in turn allows users to mine information such as the extents and relative likelihoods of extreme events for each period, a key aspect that is not provided by the summary 30 -year projections available online. It was decided to generate the data as a 'worst-case scenario' so as to give the starkest picture of potential differences from baseline conditions. This meant using the SRES A1F1 emissions scenario for the end of the twenty-first century at the $90 \%$ probability level, meaning that the greatest range of outcomes could be considered. For both periods, 100 separate files were generated, each containing a 30 -year data sequence. This is deemed to be the minimum amount necessary for a robust data set (Jones et al., 2009). For each period, these files were amalgamated, giving two data sets that could be used to illustrate 30 -year climate means as well as the relative likelihood of extreme weather variables.

Comparison of the modelled baseline and projected data indicates that the general climate trends anticipated for the UK as a whole can be expected to be similar in the Carse of 
Gowrie. A significant increase in mean annual temperature of up to $3.8^{\circ} \mathrm{C}$ has the caveat of an increase in summer temperatures of up to $2 \cdot 0^{\circ} \mathrm{C}$ more than for winter, although the projected increase in mean minimum winter temperatures may be particularly significant in reducing the expected number of daily freeze-thaw cycles per year (Figure 1). Indeed, comparison of the days in each parent data set where the minimum temperature drops below $0^{\circ} \mathrm{C}$ and the maximum exceeds $0^{\circ} \mathrm{C}$ indicates a drop of the order of $44 \mathrm{~d}$ each year.

The projected change in mean annual precipitation is negligible, but it is clear that seasonal shifts can be anticipated, with a projected increase of up to $0.7 \mathrm{~mm} / \mathrm{d}$ in the winters of the $2080 \mathrm{~s}$ and a decrease of $0.4 \mathrm{~mm} / \mathrm{d}$ in the summers of the same period (Figure 2). This may mean an increased likelihood of winter flooding events followed by extended drier periods and therefore the exacerbation of swell-shrink cycles within earthen materials. Furthermore, it may also be that the behaviour of water within and around earth buildings becomes increasingly dynamic, with warmer winter temperatures and increased quantities of water around sites reducing the number of occasions where freezing temperatures may act as a block on water penetration, encouraging further infiltration and movement within walls.

The projected changes to $\mathrm{RH}$ show no change for the winter months but a decrease of around 5\% for the summer months (Figure 3). Interestingly, this would bring the summer mean RH to $75 \%$, which would suggest a significant increase in the incidence of sodium chloride crystallisation within materials as humidity oscillates around the critical figure of $75 \cdot 3 \pm 0 \cdot 5 \%$. Furthermore, this change to summertime conditions would also increase the frequency of $\mathrm{RH}$ oscillations around $71 \%$ $\left(20^{\circ} \mathrm{C}\right)$, which Rodriguez-Navarro et al. (2000) have noted as being the point at which mirabilite $\left(\mathrm{Na}_{2} \mathrm{SO}_{4} \cdot 10 \mathrm{H}_{2} \mathrm{O}\right)$ dehydrates to form thenardite $\left(\mathrm{Na}_{2} \mathrm{SO}_{4}\right)$. Mirabilite is an expansive compound and its crystallisation poses a significant risk in relation to the structural integrity of materials. This is due in part to crypto-efflorescence (crystallisation beneath the surface of a material), which can result in the build-up of internal pressure; this is manifest in terms of cracking, surface ablation and, ultimately, loss of structural performance.

\subsection{Sampling aims}

Two buildings in the Carse of Gowrie (Figure 4) were instrumented with integrated temperature and humidity probes as part of the wider research projects from which this paper stems. The Old Schoolhouse, Cottown, and the barn at Flatfield Steading provided the opportunity to gain macroscale insights into the performance of mudwall structures in relation to weather-related stresses. Taking influence from the growing research area of heritage climatology, which is encapsulated in the work of Sabbioni et al. (2010), long-term monitoring of the external climate is contrasted with the response seen deep within the building materials through use of in situ sensors located at depth within the walls of Cottown Schoolhouse and the barn at Flatfield Steading.

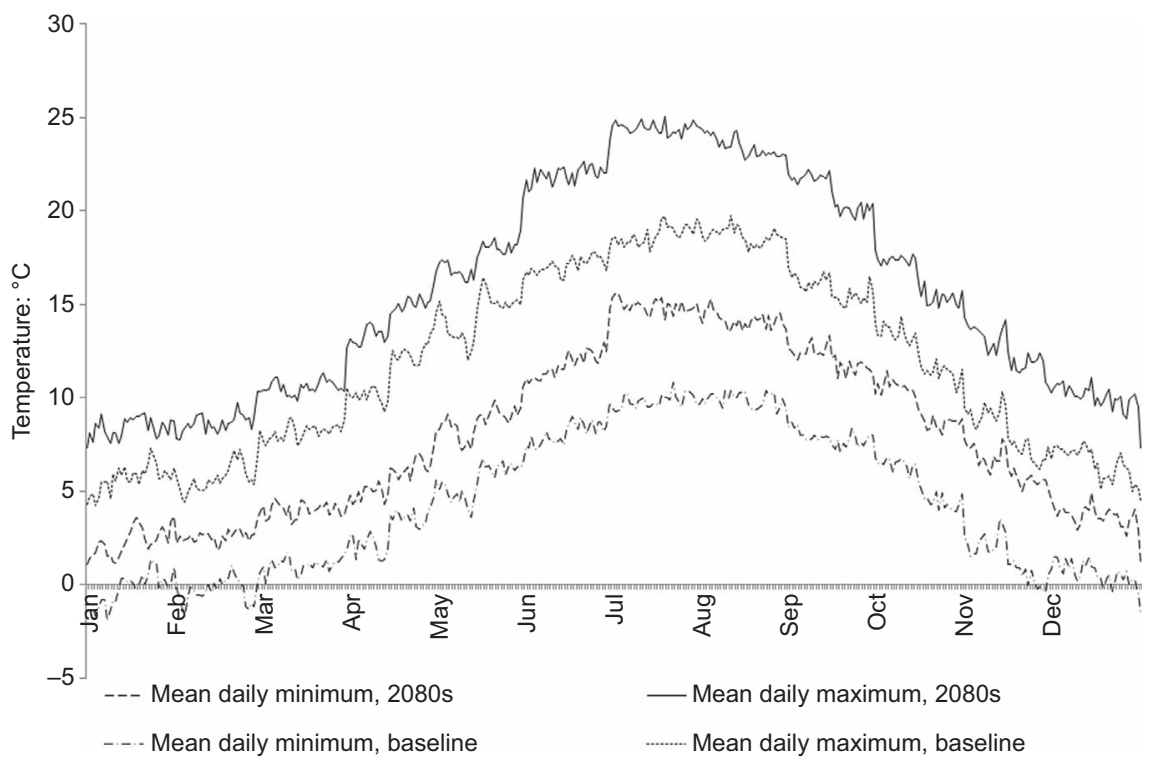

Figure 1. Baseline and future projected mean daily minimum and maximum temperatures for Errol, modelled at the $5 \mathrm{~km}^{2}$ scale using the UKCP09 weather generator 


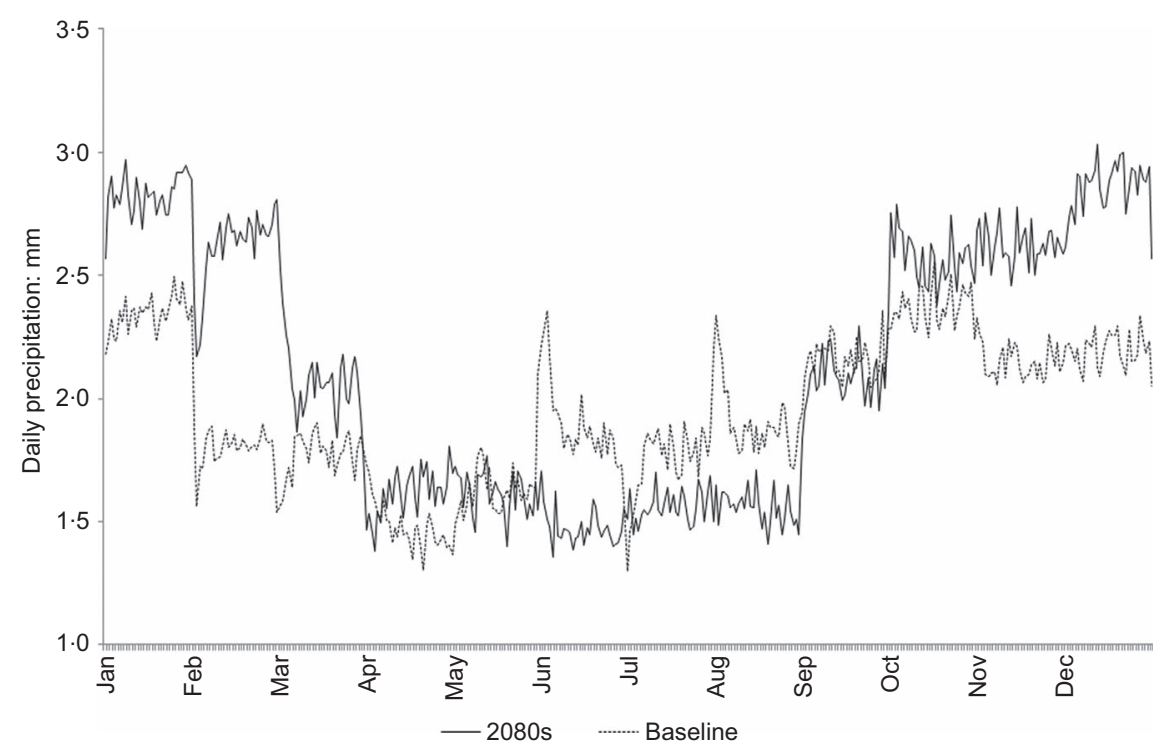

Figure 2. Baseline and future projected mean daily precipitation for Errol, modelled at the $5 \mathrm{~km}^{2}$ scale using the UKCPO9 weather generator

\subsection{The Old Schoolhouse}

The single-storeyed Old Schoolhouse in the hamlet of Cottown (Figure 5), which is adjacent to the village of St Madoes around $5 \mathrm{~km}$ west of Errol, was originally built as a squareplan mudwall cottage in the mid-eighteenth century. The mudwalls are built atop a low rubble plinth and were established to their full extent by the end of the eighteenth century, when the building was extended to the east. The roof of the schoolhouse, thatched with local Tay estuary reeds with a ridge of turf, is piended at its younger, eastern end and the

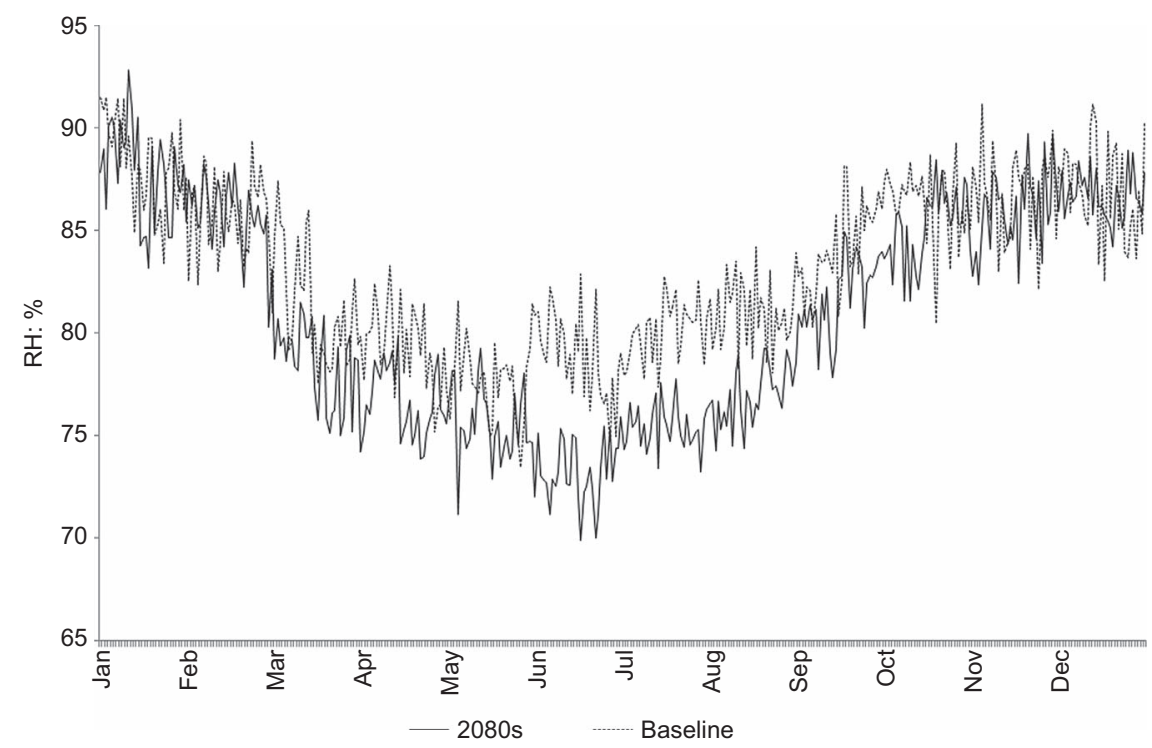

Figure 3. Baseline and future projected mean daily $\mathrm{RH}$ for Errol, modelled at the $5 \mathrm{~km}^{2}$ scale using the UKCP09 weather generator 


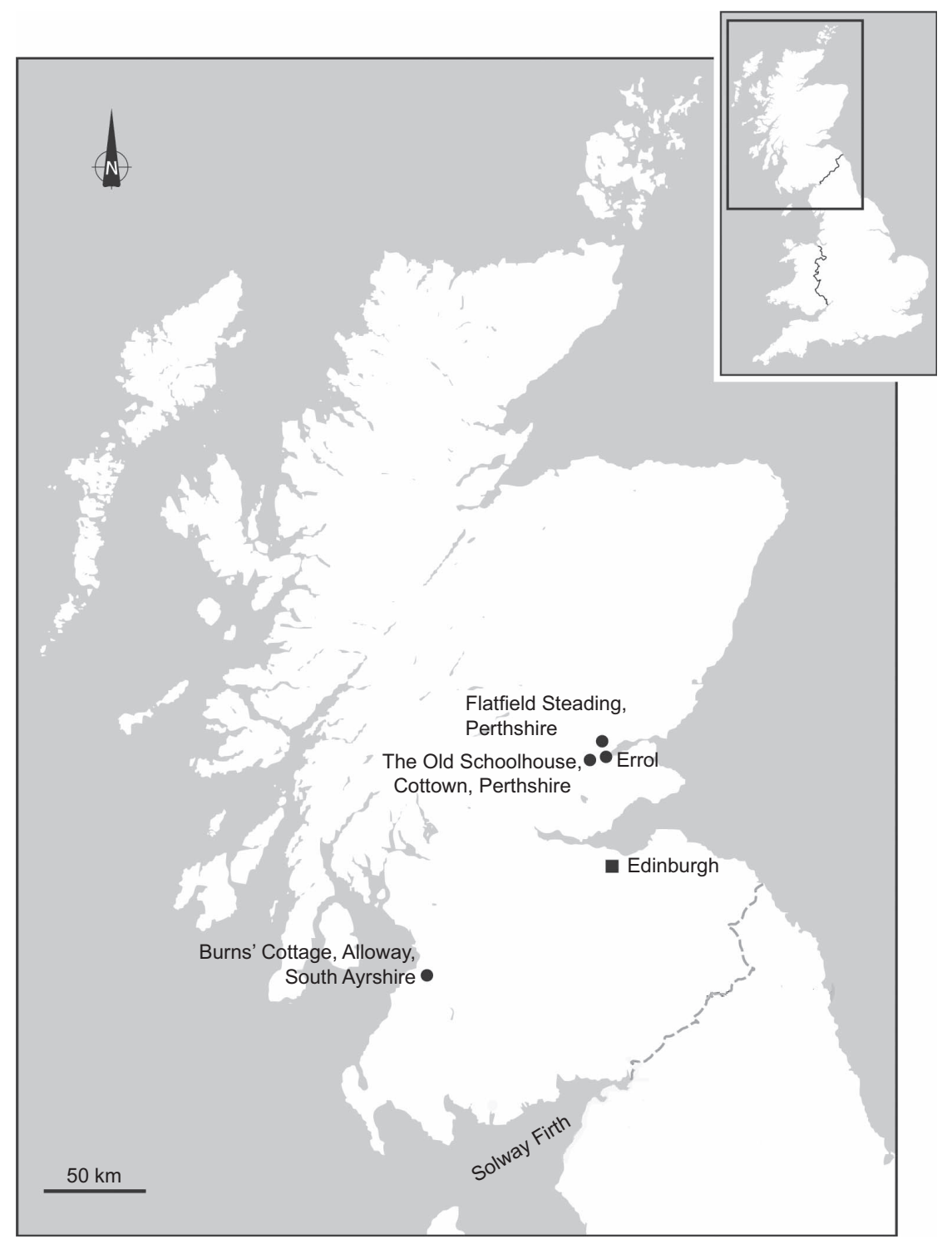

Figure 4. Map of Scotland showing Cottown Old Schoolhouse and Flatfield Steading

western wall is gabled. It is worth noting that gable walls are often the most vulnerable part of a mudwall building due to complications in their erection (Harrison, 1999). The schoolhouse was perilously close to being lost following its abandonment as a dwelling in the mid-1980s (Reen, 1999), but its significance was recognised by the National Trust for Scotland (NTS), who acquired the site in 1993 following its designation as a category A listed building the previous year (NTS, 2009).

An options appraisal for the schoolhouse produced by the NTS Little Houses Improvement Scheme (LHIS) details a number of the remedies to problems encountered since 1993 (NTS, 2009), with many of the issues being common in historic massed-earth buildings. It was noted at this time that the failure of the old thatch was permitting water ingress into the mudwalls from above, causing damage to some of the eastern wallheads. The schoolhouse suffered 'major flooding' during the 1980s (Reen, 1999) and winter flooding has become increasingly problematic at the site, with events in 2001 and 2002 leading to further repairs being made to the harling and thatch. Movement in the western gable wall prompted its stabilisation, with pre-dried cob blocks being used in isolated places to repair the base of the wall where submergence in 
Climate threats to the earth-

built heritage of Scotland

Parkin, Adderley, Kennedy et al.

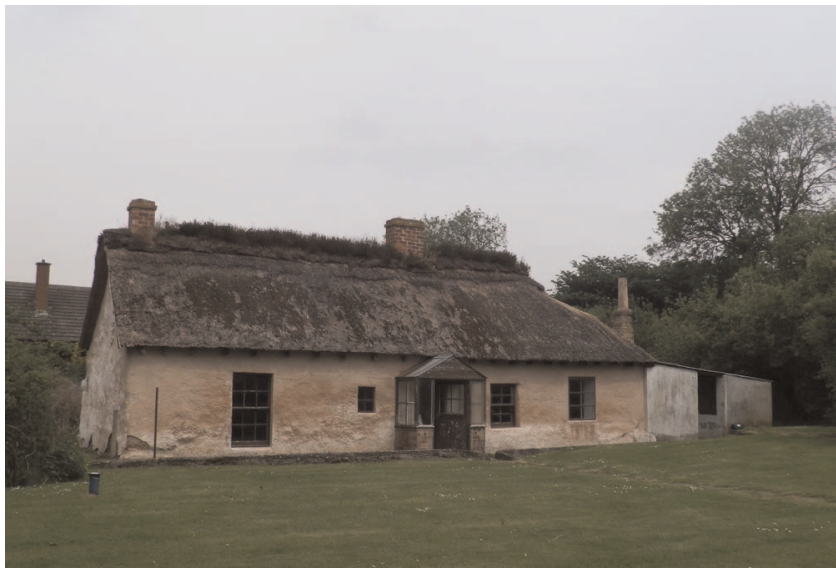

Figure 5. The Old Schoolhouse, Cottown, with instrumented western gable wall to the left end as viewed

floodwaters had caused undercutting and the loss of surface material (Forster et al., 2008). All other renewals of the original repairs were completed by 2007 , bringing the structure back to a wind- and watertight condition. Nevertheless, the schoolhouse remains at risk as the site awaits further repair and the regular maintenance that comes with occupation.

Frequent flooding and associated water ingress from the ground are undoubtedly regarded as the greatest climaterelated threats to the integrity of the schoolhouse's mudwalls, although much of the evidence relevant to assessing the performance of the schoolhouse in the face of climate-related impacts is conjectural or anecdotal. It has been suggested by local residents that the raising of the road that runs through the hamlet is related to increased incidences of localised flooding, while a local newspaper report in February 2013 indicated the belief among the same group that blocked drainage ditches are the primary cause of flooding around the building, with this being contested by the NTS (Topping, 2013). It seems, however, that the physical context of the site provides the most tangible explanation to why the schoolhouse suffers so acutely from flooding, with the building situated within the depression of a glacial drumlin. Significantly, the western gable wall rests at the lowest point of this. Furthermore, a high water table encourages flooding and discourages drainage. Episodic flooding events are inevitably followed by drying periods, which carries ramifications in terms of swelling being followed by shrinkage and cracking in the walls. As increased winter precipitation and warmer dryer summers are predicted for the remainder of the twenty-first century, it seems that the long-term survival of the schoolhouse (and its equivalents around Scotland and further afield) is partly dependent on improving understanding of the performance of mudwalls over the course of annual seasonal transitions.

\subsection{Flatfield Steading barn}

The mixed farm at Flatfield (Figure 6), around $3 \mathrm{~km}$ north of Errol, was established in 1785 and has been in the possession of the family that now occupies it since 1825 (Walker and Walker, 1989). Part of the Errol parish, the site comprises the main farmhouse together with agricultural outbuildings laid out in a square plan. The main farmhouse is built from bricks apparently fired on-site in clamp kilns, while the older outbuildings were all erected with mass-earth walls. A depression in a field to the south-east of the main house is said to denote the pit from where clay was procured for producing bricks for the house and building the single-storey cart shed (now used as a cattery), the one-and-a-half storey barn and its adjoining two-storey extension. The techniques used in the construction of the mass-earth walls are subject to debate, with the suggestion of Walker and Walker (1989) that the pisé method was used being undermined by the fact that fibre additives were included in the mix, as is typical of the mudwall method, while the walls themselves are tapered to the top and are devoid of tell-tale markings that would have been left by rammed earth shuttering (Whyte, 2010). The claywall method was certainly used for the parts of the twostorey barn that are faced with stone and it may be that temporary shuttering was used as a guide rather than formwork for ramming the unfaced walls.

Like many mass-earth buildings around the world, the barn and ancillary outbuilding closer to the main house at Flatfield were coated in cement render in the 1970s and the rate of deterioration that has occurred in the gable end of the barn within the last 40 years is alarming. Indeed, the gable itself which was most recently comprised of brick, presumably as a replacement for original earthen material - is now completely lost, with the extant mass-earth wall reaching eaves height. Furthermore, the barn was subject to even greater short-term risk when high winds in 2011 ripped the roof from the structure, exposing the historic rafters and walls on two sides.

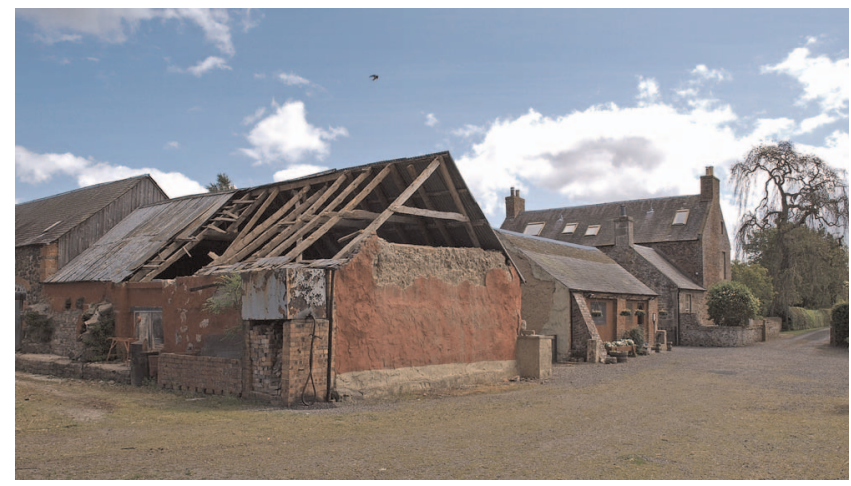

Figure 6. Flatfield Steading, with the instrumented western gable end of the barn building in the foreground 
Engineering History and Heritage

Volume 168 Issue EH1
Climate threats to the earth-

built heritage of Scotland

Parkin, Adderley, Kennedy et al.
The owners of the farm were proactive at this time, however, and secured the structural integrity of the barn for the foreseeable future by replacing the lost roof and using weatherboards to protect the exposed wallhead at the gable end.

\section{Methods}

2.1 Placement of temperature and humidity sensors in the building fabric of the Old Schoolhouse and Flatfield barn

The instrumented buildings around the town of Errol are both unheated earth-built structures. Sensors were placed in the wall fabrics of Cottown Schoolhouse and Flatfield Steading barn as part of two sets of research studies. Since each building was being studied by different research teams and for originally quite different purposes, there are slight variations in the sensor type used and in probe placement methodology. However, following the protocol of minimal intervention integral to conservation philosophy it was decided to maintain the sensors initially placed.

Five standalone sensors were placed with the aim of temperature and RH monitoring at Cottown Schoolhouse (EL-USB-2-LCD EasyLog temperature and humidity USB, Lascar Electronics, UK) (Figure 7), with the results from the three in-wall sensors being considered here. The sensor measurement ranges were $-35^{\circ} \mathrm{C}$ to $+80^{\circ} \mathrm{C}$ with an accuracy of $\pm 0.5^{\circ} \mathrm{C}$ and $0-100 \%$ with an accuracy of $\pm 3 \%$ for temperature and $\mathrm{RH}$ respectively. The probes recorded temperature and humidity twice per hour per day. The first two probes were inserted into the wall at heights of $0.3 \mathrm{~m}$, with the third at $1.0 \mathrm{~m}$. The sensors are about $2 \mathrm{~cm}$ in diameter and $12.5 \mathrm{~cm}$ in length, with core-bit drilled holes accommodating these exactly to ensure that physical disturbance of the building fabric was low. The probes were relocated on 26 April 2012 to heights of $1.2 \mathrm{~m}$ and $1.7 \mathrm{~m}$ above ground and $0.5 \mathrm{~m}$ above the eaves (approximately $2.9 \mathrm{~m}$ from the ground) because of saturation due to high moisture content within the walls, which causes damage to the sensors and inhibits the monitoring of humidity fluctuations. Another disadvantage arising from this situation is that the moisture

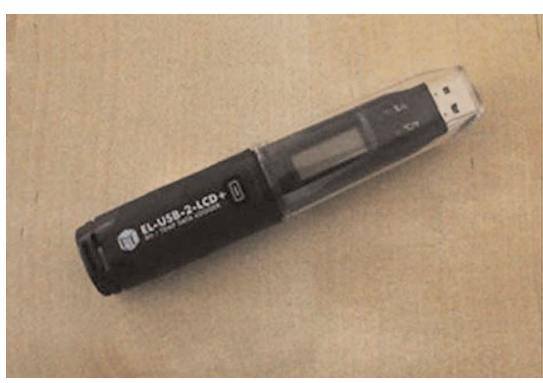

Figure 7. The integrated temperature and RH sensors used at Cottown (left) and Flatfield (right) content cannot be derived based on $\mathrm{RH}$ values higher than $95 \%$ using sorption isotherms (BSI, 2000).

The north and west walls of the barn at Flatfield Steading were instrumented with integrated sensor and dataloggers (DS1923 Hygrochron iButton, Maxim Integrated Corp., San Jose, USA) (Figure 7). These sensors are capable of measuring temperatures ranging between $-20^{\circ} \mathrm{C}$ and $85^{\circ} \mathrm{C}$ at an accuracy of $\pm 0.5^{\circ} \mathrm{C}$, as well as RH at an accuracy of $\pm 5 \%$. These were identified as a particularly appropriate means of internally instrumenting mass-earth walls given the minimal intrusion afforded by their small size $(17.35 \mathrm{~mm}$ diameter and $5.89 \mathrm{~mm}$ depth). Following a practice devised and empirically tested by Historic Scotland for their experimental studies of masonry walls, each iButton sensor was placed within a tampon formed of muslin cloth and inserted into a drilled hole at a depth of $200 \mathrm{~mm}$ from the external wall face. The hole was backfilled with locally sourced clay from the disused Errol brickworks. One sensor was located at a height of $0.5 \mathrm{~m}$ above ground level in the western end of the north wall and the other was located at the centre of the west wall at first-floor level. Measurements were recorded twice daily, at 01:00 and 13:00.

\subsection{External weather conditions}

Regional monthly and daily weather data were obtained from the permanent weather station located at the James Hutton Institute, Invergowrie, located $12 \mathrm{~km}$ east of Errol, for the period from January 2011 to April 2013. These data provide a reference for conditions in the area throughout the time that temperature and humidity monitoring within the walls of the schoolhouse and barn took place. Following the example of Sabbioni et al. (2010), mean daily minimum and maximum temperatures and mean daily precipitation levels are shown in Table 1, together with total monthly precipitation and determinations of the number of frost and wet days.

\subsection{Time series statistical analysis}

The time series data from both the external climate and in situ measurements require comparison within and between

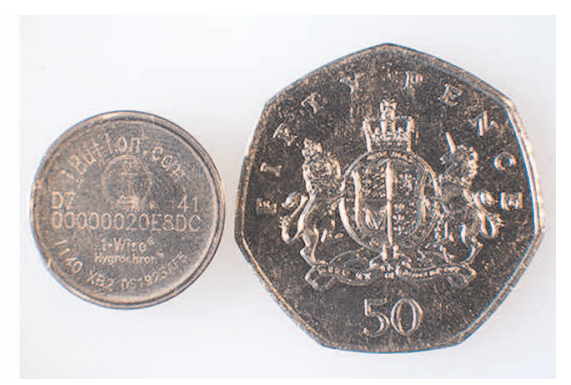




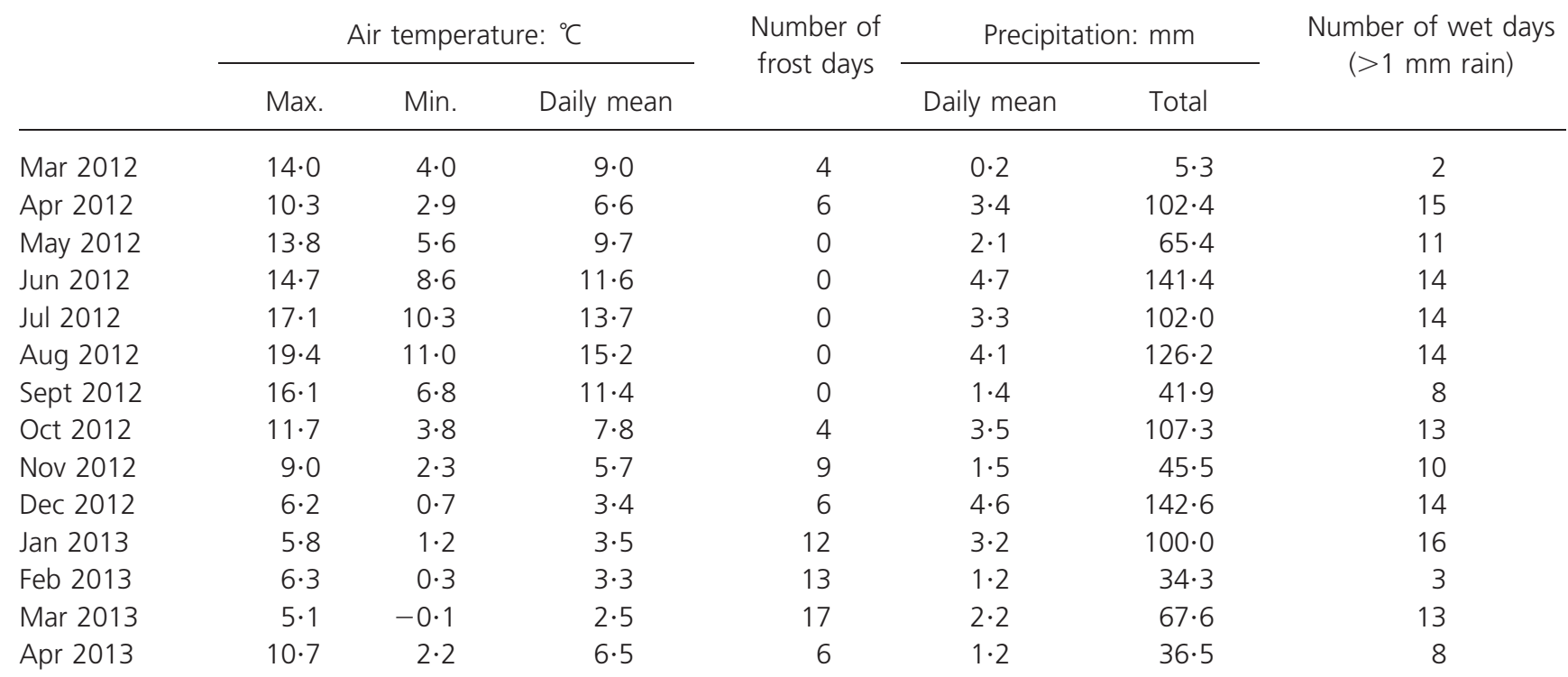

Table 1. Monthly weather observations at the James Hutton Institute (JHI), Invergowrie, Dundee, March 2012 to April 2013

data sets. A series of statistical analyses examining underlying trends in the data was made and visually presented as a set of decomposed time series. These were calculated and plotted using the time series analysis functions of $\mathrm{R}$ statistical software (RDCT, 2008). Decomposition of the plots allows trends to be established and visually compared. Using observed temperatures, Figure 8 illustrates this with rolling weekly, monthly and quarterly averages (i.e. $7 \mathrm{~d}, 30 \mathrm{~d}$ and $90 \mathrm{~d}$ ) being calculated for the underlying trend. The 'random' component can be seen as variation within these trends. For the purposes of comparison with long-term forecasts of climate change between presentday baselines and the year 2080, monthly decompositions were calculated for each data set from each sensor.

\section{Results and discussion}

\subsection{Internal wall data observations}

Table 2 provides a summary of the internal wall observations at each site and Figure 9 indicates the spread in data across the sampling period. The relative temperatures exhibited for the gable wall of the Cottown Schoolhouse remained consistent between each probe, with slightly higher temperatures observed at greater height reflecting a difference in mean temperature between the lowest and highest probes of $0 \cdot 6^{\circ} \mathrm{C}$. The diurnal temperature data obtained from the walls at Flatfield barn also revealed differences depending on the height at which the sensors were located within the wall, with the difference in overall means being $0 \cdot 9^{\circ} \mathrm{C}$. Between November and February, however, the difference in mean temperature between the two sensors was reduced. Daily temperature changes within the gable wall of the schoolhouse tended to be delayed in relation to external temperatures, rising from late morning or afternoon and being maintained until late at night before falling over the course of the early morning hours. The range in temperatures recorded at Cottown was $18 \cdot 0^{\circ} \mathrm{C}$ at the lowest level and $19 \cdot 0^{\circ} \mathrm{C}$ at the two higher levels. Night-time temperature within the wall at Flatfield was warmer on average by $0.5^{\circ} \mathrm{C}$ at first-floor level and by $0 \cdot 2^{\circ} \mathrm{C}$ at $50 \mathrm{~cm}$ height; the upper sensor also recorded greater variation in temperature over the course of time and retained heat through the night, with a maximum of $20 \cdot 6^{\circ} \mathrm{C}(28$ May $2012,01: 00)$ compared with $17 \cdot 1^{\circ} \mathrm{C}$ at $50 \mathrm{~cm}$ (19 August 2012, 01:00). This emphasises the thermal performance of massearth walls, which clearly retain the heat absorbed during the day well into the night.

It should also be noted that, although the external temperature frequently dropped to well below $0{ }^{\circ} \mathrm{C}$ during the data collection period, the temperature recorded within the walls at both sites stayed above freezing throughout, with the only exception being 13-15 December 2012. This is perhaps key to explaining the resilience of the schoolhouse. The minimum external temperature for the entire period was recorded on 13 December 2012, occurring within a four-day spell when minimum temperatures were consecutively $-2.9^{\circ} \mathrm{C},-3.0^{\circ} \mathrm{C}$, $-5.7^{\circ} \mathrm{C}$ and $-3.0^{\circ} \mathrm{C}$. Sensor 1 at Cottown Schoolhouse recorded a temperature of $-0.5^{\circ} \mathrm{C}$ at $00: 13$ on 13 December 2012, with sensor 2 recording a fall below freezing over $4 \mathrm{~h}$ later. Sensor 3 followed suit by 14:43 the following afternoon, 

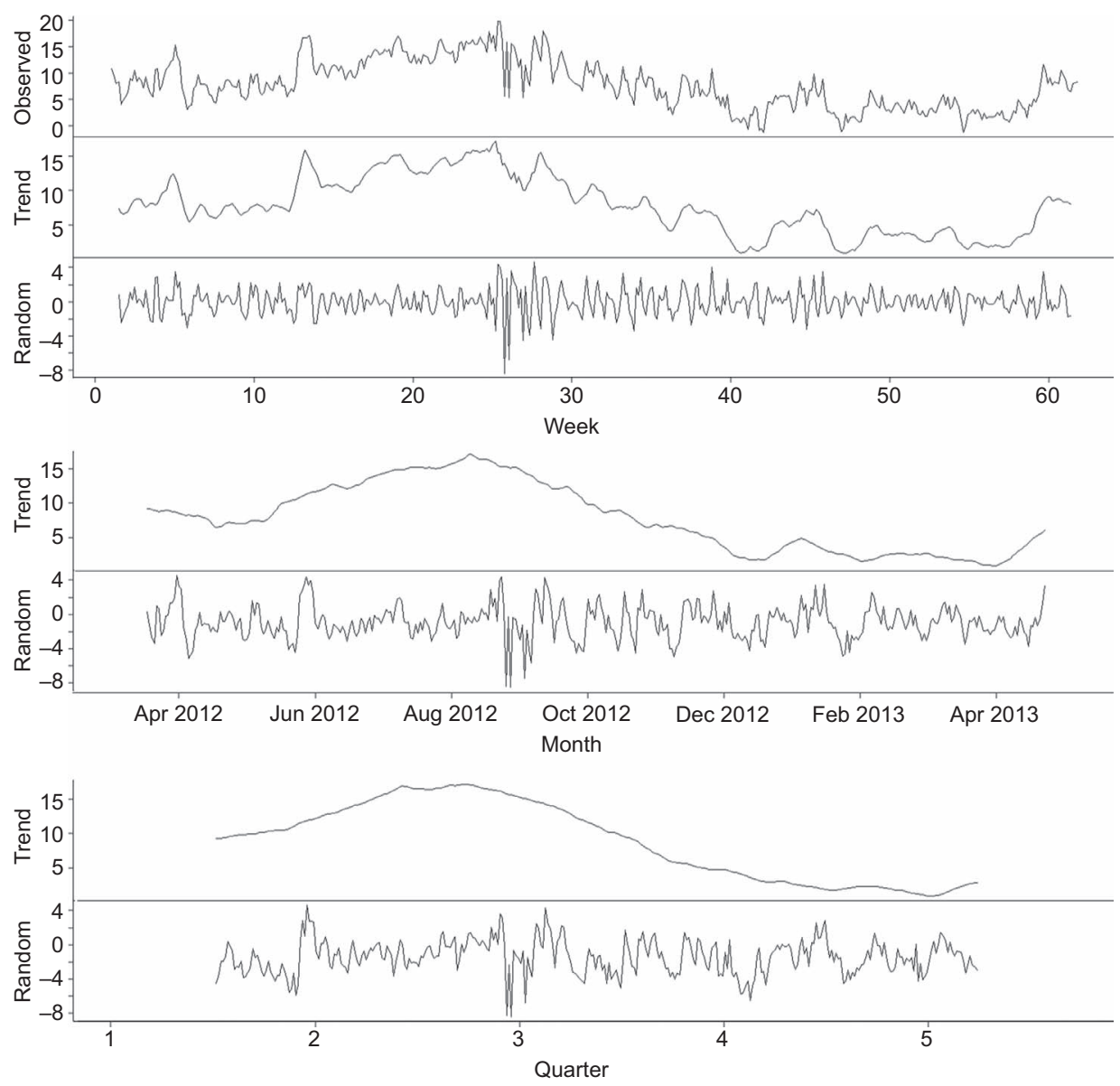

Figure 8. Example time series decomposition plots based on external temperature observations, showing trends on a weekly, monthly and quarterly basis. Plots were generated at these scales for all data discussed in the paper and are referred to through the discussion

staying at $0 \cdot 5^{\circ} \mathrm{C}$ until the next evening. Sensors 1 and 2 fell to $-1 \cdot 0^{\circ} \mathrm{C}$ with the same rate of lag and maintained this temperature over the course of the day before rising over the early evening (sensor 2) and night-time (sensor 1) of 14 December 2012. Conversely, the minimum temperature at Flatfield barn of $-2 \cdot 0^{\circ} \mathrm{C}$ (13 December 2012, 13:00) was recorded at first-floor height, while that at $50 \mathrm{~cm}$ from ground level never went below $0 \cdot 5^{\circ} \mathrm{C}$ (13-14 December 2012). This may be explained by the exposure of the upper level of the wall. Overall mean temperatures increased with height in both structures, with the implication that greater levels of wetness within the material at the bottom part of each wall are highlighted by lower temperatures within the walls.

Removing the data for the schoolhouse up to and including April 2012 reveals a consistency in the RH measurements recorded by each probe. Interestingly, sensor 2 logged the highest $\mathrm{RH}$ throughout, ranging between $92 \cdot 0 \%$ and $98 \cdot 5 \%$ with a mean of $94.9 \%$, perhaps as a consequence of ingress from above due to thatch failure. This compares with means of $94 \cdot 1 \%$ for sensor 1 and $93 \cdot 1 \%$ above the eaves. All three probes recorded significantly higher $\mathrm{RH}$ than at Flatfield, with exception to very limited cross-over in the data for the upper probes at each structure, and with notably lesser range. This presumably reflects the impacts of increased levels of water ingress at Cottown resulting from both ground saturation and the potential failure of the thatch allowing water to seep from above. The difference between day-time and night-time $\mathrm{RH}$ recorded at Flatfield was negligible compared with the differences between the two locations, with the mean $\mathrm{RH}$ at $50 \mathrm{~cm}$ being more than $5 \%$ greater than at first-floor height. The maximum $\mathrm{RH}$ recorded at $50 \mathrm{~cm}$ was $93 \cdot 4 \%$ (25 March 2013, 13:00) and the lowest was 84·3\% (02 March 2012, 01:00); at first-floor height the maximum recorded $\mathrm{RH}$ was $90 \cdot 1 \%$. 


\begin{tabular}{|c|c|c|c|c|c|c|c|c|c|c|}
\hline & \multicolumn{6}{|c|}{ Old Schoolhouse, Cottown } & \multicolumn{4}{|c|}{ Flatfield Steading barn } \\
\hline & \multicolumn{2}{|c|}{ Sensor 1 at $1 \cdot 2 \mathrm{~m}$} & \multicolumn{2}{|c|}{ Sensor 2 at $1.7 \mathrm{~m}$} & \multicolumn{2}{|c|}{ Sensor 3 at $2.9 \mathrm{~m}$} & \multicolumn{2}{|c|}{ Sensor at $0.5 \mathrm{~m}$} & \multicolumn{2}{|c|}{ Sensor at first floor } \\
\hline & Temp: ${ }^{\circ} \mathrm{C}$ & RH: \% & Temp: ${ }^{\circ} \mathrm{C}$ & RH: \% & Temp: ${ }^{\circ} \mathrm{C}$ & RH: \% & Temp: ${ }^{\circ} \mathrm{C}$ & RH: \% & Temp: ${ }^{\circ} \mathrm{C}$ & RH: \% \\
\hline Mean & $7 \cdot 9$ & $94 \cdot 1$ & $8 \cdot 3$ & $94 \cdot 9$ & $8 \cdot 6$ & $93 \cdot 1$ & $8 \cdot 2$ & $89 \cdot 5$ & $9 \cdot 1$ & $85 \cdot 2$ \\
\hline Std dev. & $5 \cdot 0$ & $0 \cdot 4$ & $4 \cdot 9$ & 0.5 & $5 \cdot 1$ & 0.5 & $4 \cdot 3$ & $1 \cdot 7$ & $4 \cdot 9$ & $2 \cdot 3$ \\
\hline Min. & $-1 \cdot 0$ & $92 \cdot 0$ & $-1 \cdot 0$ & $92 \cdot 0$ & -0.5 & $89 \cdot 0$ & 0.5 & $84 \cdot 3$ & $-2 \cdot 0$ & $81 \cdot 4$ \\
\hline Max. & $17 \cdot 0$ & $96 \cdot 0$ & $18 \cdot 0$ & $98 \cdot 5$ & $18 \cdot 5$ & $94 \cdot 5$ & $17 \cdot 1$ & $93 \cdot 4$ & $20 \cdot 6$ & $90 \cdot 1$ \\
\hline Range & $18 \cdot 0$ & $4 \cdot 0$ & $19 \cdot 0$ & $6 \cdot 5$ & $19 \cdot 0$ & $5 \cdot 5$ & $16 \cdot 5$ & $9 \cdot 1$ & $22 \cdot 6$ & $8 \cdot 7$ \\
\hline
\end{tabular}

Table 2. Summary table of temperature and RH data recorded from within the mass-earth walls at Cottown and Flatfield from March 2012 to April 2013 (RH data for Cottown during March and April 2012 omitted due to sensor saturation)

\subsection{Time series decompositions}

Figures 10 and 11 show the original observations, underlying trends on a monthly basis and the variations within trends over the course of the sampling period for each of the external weather parameters and dataloggers. In the figures, the top three sets of plots show external temperature, precipitation and wind speed (in knots; 1 knot $=1.85 \mathrm{~km} / \mathrm{h}$ ). The bottom two sets of three plots show temperature and RH data for one of the dataloggers used at each location. It should be noted that the RH data for Cottown were interpolated for the first two months using the mean monthly data for March and April 2013.

Examination of the decomposed time series plots (Figure 10 for Cottown and Figure 11 for Flatfield are given as examples

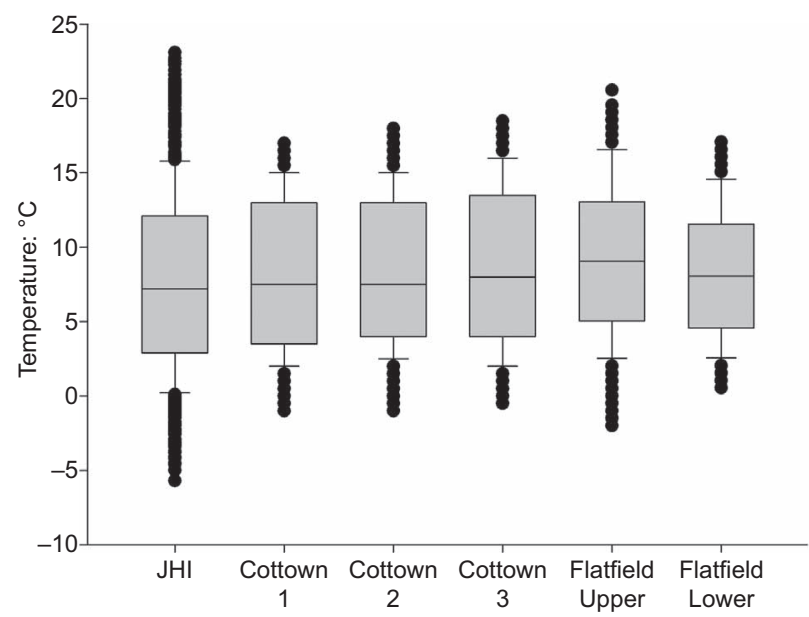

Figure 9. Spread of observed data for temperature, both externally and within the walls of the structures, and for $\mathrm{RH}$ within the walls of each structure of outputs when data are decomposed at the monthly scale) indicates some interesting trends in the patterns of weather over the period of interest. There was a prolonged depression in temperature in April 2012 and an inverse relationship between temperature and wind speed is also suggested. This reinforces the expectation of greater stability in weather during the summer months. The lowest wind speeds were also recorded concurrently with extremely high precipitation in summer 2012. As already noted, this did not lead to any known flooding at the site and this therefore suggests that efficient evaporation of water from around the site is reliant mainly upon temperature. Increased wind speed in winter periods has direct impacts in terms of increased incidences of rain being driven onto the walls of the buildings during a time of vulnerability. This is especially relevant to the western gable at

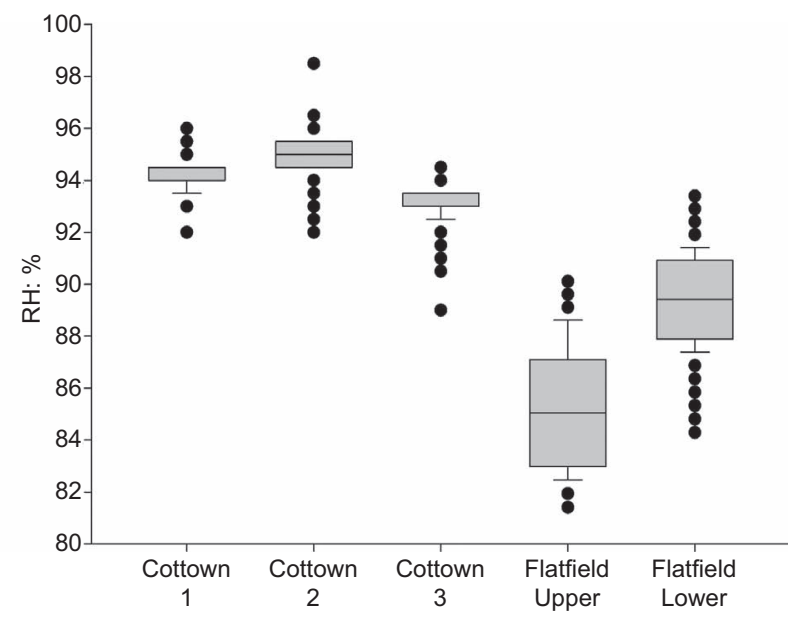




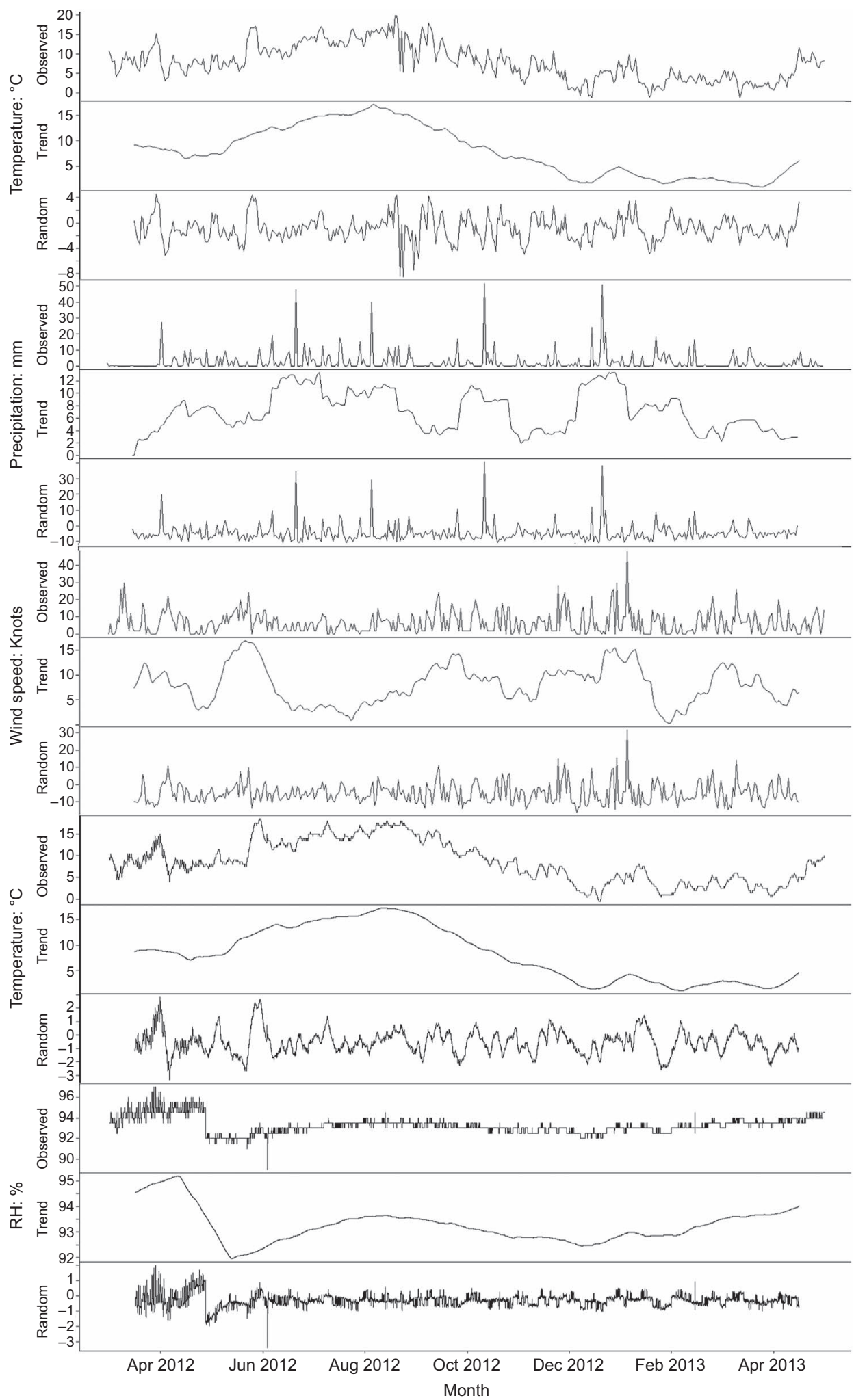

Figure 10. Example time series decomposition plots showing monthly trends for external weather observations (upper three plots of temperature, precipitation and wind speed) and temperature and RH data collected by sensor 3 within the Old Schoolhouse, Cottown (lower two plots) 


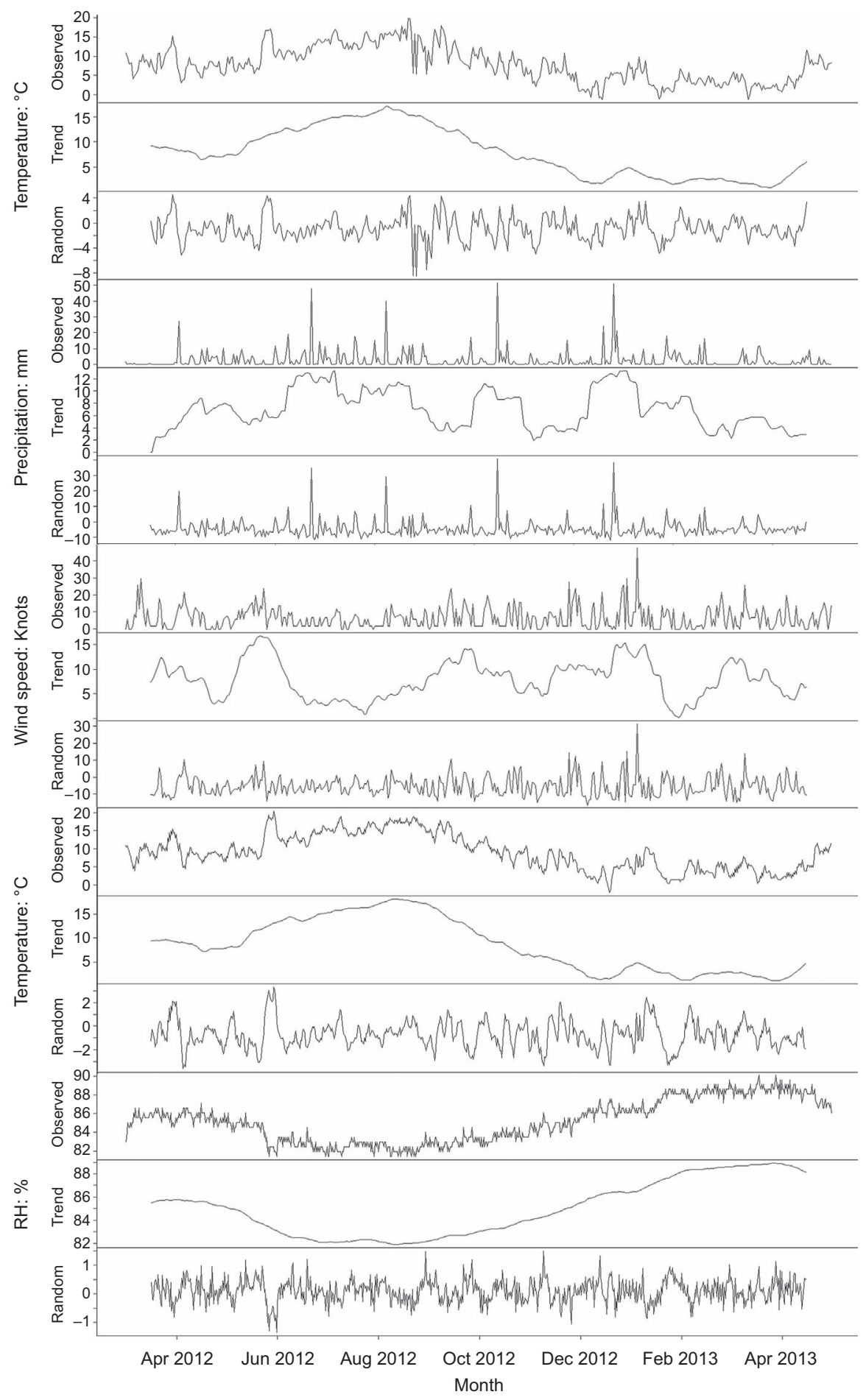

Figure 11. Example time series decomposition plots showing monthly trends for external weather observations (upper three plots of temperature, precipitation and wind speed) and temperature and RH data collected by the sensor at first-floor height within the barn outbuilding at Flatfield (lower two plots) 
Engineering History and Heritage

Volume 168 Issue EH1
Climate threats to the earth-

built heritage of Scotland

Parkin, Adderley, Kennedy et al. the schoolhouse as the prevailing winds in the Carse of Gowrie are from the south-west. Of particular utility, however, are the monthly decompositions of precipitation data, which are difficult to interpret when presented as daily observations alone as the eye tends to be drawn to the most pronounced spikes without fully appreciating the effects of lower-level precipitation. Although the winter-spring of 2012-2013 may not be representative of future predicted conditions in respect of winter freezing events (there are likely to be fewer still), it reflects the predicted increase in the regularity of extreme events, thus making it a very useful case study.

As would be expected, there is a clear correlation between the temperatures recorded externally and within the walls of each structure, with the known lag in response being too short to notice over the long-term plots. It is worth noting that the data for the probes at Cottown include a period of increased randomness during the same time as when $\mathrm{RH}$ values could not be recorded due to sensor saturation. Differences in $\mathrm{RH}$ are apparent between locations with elevated humidity when temperature is reaching its summer peak, while precipitation levels are falling and wind speed is at its lowest. It should be noted, however, that precipitation remains noteworthy throughout this time, even if exhibiting a falling trend, and these humps in $\mathrm{RH}$ for the data recorded higher in the wall may indicate water ingress from above due to a failure of the thatch. The fact that the lower probe did not show any increase in $\mathrm{RH}$ over the same period corroborates the suggestion that groundwater threats are alleviated by increased summer evaporation rates. For the period in which the upper probes at the schoolhouse show humps in their RH data, the sensor data from Flatfield remain smooth and follow the expected seasonal trend, which seems to support the possibility of water ingress from above being picked up in the schoolhouse data. The RH for the lower part of the Flatfield wall shows a slightly earlier and more accelerated increase from the latter part of the second quarter when compared with that for the higher part of the wall. This presumably reflects the impacts of increased uptake of groundwater as temperatures fall and external RH rises concurrently, with only the latter phenomenon being expressed through the data for the higher sensor.

\section{Conclusion}

Pronounced responses to the observed conditions are seen in the data for each of the case studies. The temperature and $\mathrm{RH}$ loggers at both locations indicate a number of pertinent results highlighting the resilience of the mass-earth walls to extremes of temperature, particularly freezing conditions, which was unexpected from earlier experimental studies. The contrast between these experimental studies, which predicted potentially disastrous impacts on such buildings, and the resilience seen in the buildings examined in this paper suggests that scaling of experimental models should be done with care when applied to vernacular architectures worldwide.

The investigations outlined here represent a novel and easily replicable approach to directly assessing the responses of massearth buildings to the variable external weather conditions experienced in Scotland during the period of study. This approach can serve to complement and augment methods used by engineers to assess physical performance through strength, ablation and loading tests. Climate models project increases in short-term extreme weather events throughout the Northern Hemisphere by the 2080s. The data analysed in this paper can therefore be seen as an example of the types of future scenarios to be increasingly expected further afield. The consideration of places that already experience pronounced variability in weather, such as Scotland, thus offers the potential to add insight to the performance of universally recognisable styles of historic structure such as those built with mass earth.

The use of time series decompositions allows an additional layer of inference to be drawn from the raw data acquired at each site and can be used to indicate trends at whatever timescale may be required. While the winter-spring of 2012 2013 may not necessarily be representative of future predicted conditions in respect of winter freezing events in Scotland (there are likely to be fewer still in 2080), the data considered here suggest persisting but changing risks of future extreme events.

\section{Acknowledgements}

The authors would like to acknowledge Historic Scotland, the University of Stirling and the Parnassus project for collectively funding the work reported in this paper. We kindly thank the National Trust for Scotland for the provision of architectural drawings of Cottown Schoolhouse and permission to examine the fabric of the building, the Eddy family for access to the building at Flatfield Farm, Bill Jamieson of the University of Stirling for cartographic assistance, and Tom Morton and Paul Higginson from Arc Architects for their assistance in the monitoring of Cottown Schoolhouse.

\section{REFERENCES}

BSI (2000) BS EN ISO 12571: 2000: Hygrothermal performance of building materials and products. Determination of hygroscopic properties, BSI, London, UK.

Forster AM, Medero GM, Morton T and Buckman J (2008) Traditional cob wall: response to flooding. Structural Survey 26(4): 302-321.

Harrison R (1999) Earth: The Conservation and Repair of Bowhill, Exeter: Working with Cob. English Heritage Research Transactions, Volume 3. Maney, London, UK. Historic Scotland (2002) Passed to the Future: Historic 
Scotland's Policy for the Sustainable Management of the

Historic Environment. Historic Scotland, Edinburgh, UK. Historic Scotland (2011) Scottish Historic Environment Policy.

Historic Scotland, Edinburgh, UK.

Historic Scotland (2012) A Climate Change Action Plan for

Historic Scotland 2012-2017. Historic Scotland,

Edinburgh, UK.

Jenkins G, Murphy J, Sexton D et al. (2010) UK Climate

Projections: Briefing Report. Met Office Hadley Centre,

Exeter, UK.

Jones C, Kilsby C, Harpham C, Glenis V and Burton A (2009) UK

Climate Projections Science Report: Projections of Future

Daily Climate for the UK from the Weather Generator.

University of Newcastle, Newcastle upon Tyne, UK.

Keefe L (2005) Earth Building: Methods and Materials, Repair and Conservation. Taylor and Francis, Abingdon, UK.

Met Office (2014) What is UKCP09? See http://

ukclimateprojections.metoffice.gov.uk/ (accessed 14/11/2014).

Morton T and Winship H (2012) Clay Building Rapid Survey

Report. Tay Landscape Partnership, Perth, UK.

NTS (National Trust for Scotland) (2009). The Old Schoolhouse,

Cottown: LHIS Options Appraisal. NTS, Edinburgh, UK.

RDCT (R Development Core Team) (2008) R: A Language and
Environment for Statistical Computing. R Foundation for Statistical Computing, Vienna, Austria.

Reen K (1999) Case Study: The Old Schoolhouse, Cottown, Perthshire. Context 63, IHBC, Tisbury, UK. See http:// ihbc.org.uk/context_archive/63/schoolhouse/cottown.html (accessed 13/08/2014).

Rodriguez-Navarro C, Doehne E and Sebastian E (2000) How does sodium sulfate crystallize? Implications for the decay and testing of building materials. Cement and Concrete Research 30(10): 1527-1534.

Sabbioni C, Cassar M and Brimblecombe P (eds) (2010) The Atlas of Climate Change Impact on European Cultural Heritage: Scientific Analysis and Management Strategies. Anthem Press, London, UK.

Topping K (2013) Fears for historic Cottown Schoolhouse. See http://www.thecourier.co.uk/news/local/perth-kinross/ fears-for-historic-cottown-schoolhouse-1.68308 (accessed 13/08/2014).

Walker K and Walker B (1989) Flatfield: an independent Scottish farm. Vernacular Architecture 13: 10-14.

Whyte V (2010) A Study of the Historic Earth Structures in the Carse of Gowrie. Unpublished Masters' thesis, University of Dundee, Dundee, UK.

\section{WHAT DO YOU THINK?}

To discuss this paper, please email up to 500 words to the editor at journals@ice.org.uk. Your contribution will be forwarded to the author(s) for a reply and, if considered appropriate by the editorial panel, will be published as discussion in a future issue of the journal.

Proceedings journals rely entirely on contributions sent in by civil engineering professionals, academics and students. Papers should be 2000-5000 words long (briefing papers should be $1000-2000$ words long), with adequate illustrations and references. You can submit your paper online via www.icevirtuallibrary.com/content/journals, where you will also find detailed author guidelines. 